\title{
A "HISTÓRIA DA CULTURA BRASILEIRA" E O MODERNISMO-CONSERVADOR NA DITADURA CIVIL-MILITAR (1972-1976)
}

\section{Tatyana de Amaral Maia1}

A participação de intelectuais nos projetos de modernização da nação ou no interior do Estado ao longo do período republicano brasileiro tem sido objeto de estudo da historiografia desde os anos de 1980. Destacam-se os trabalhos pioneiros de Nicolau Sevcenko, Sérgio Miceli, Daniel Pécaut e, posteriormente, Angela de Castro Gomes, Lúcia Lippi de Oliveira, Monica Pimenta Velloso, entre outros ${ }^{2}$. Os intelectuais, desde os anos de 1920, se empenharam em buscar alternativas para os destinos da nação e sinalizaram a urgência do ingresso do país na modernidade, buscando modelos para superar aquilo que consideravam as mazelas nacionais. Dentre as correntes intelectuais do período, o modernismo foi, sem dúvida, um movimento de inflexão na construção de projetos de nação, desdobrando-se em diferentes e concorrentes projetos culturais e políticos.

Durante o primeiro governo de Getúlio Vargas (1930-1945), intelectuais identificados com diferentes vertentes do modernismo ingressaram nas fileiras do Estado e passaram a concorrer na orientação dos projetos políticos, cuja legitimidade era reforçada a partir dos elementos que comporiam a cultura e a consciência nacional. Conhecer a nossa formação histórica, buscar os traços estruturantes da cultura, identificar as matrizes do funcionamento social eram ações consideradas imprescindíveis para compreender o "povo" brasileiro em sua singularidade frente a outras nações. Consequentemente, os intelectuais também passaram a disputar espaço no campo cultural pela definição das chaves-explicativas do "ser" brasileiro, prevalecendo uma visão essencialista da cultura. Para esses intelectuais, a cultura brasileira só pode ser definida através de uma investigação cultural que contemple o estudo da formação histórica da sociedade. A identidade remete à origem de um determinado grupo que supostamente caracterizaria o indivíduo de maneira autêntica. Tal compreensão da identidade cultural como reflexo das raízes constitutivas de um grupo social aparece tanto nas leituras "naturalistas" como "culturalistas" realizadas pelas ciências sociais. Neste caso, nos interessa, sobretudo, as leituras culturalistas da formação de determinada identidade cultural.

\footnotetext{
${ }^{1}$ Doutora em História pela Universidade do Estado do Rio de Janeiro. Realizou estágio pós-doutoral junto à Universidade do Porto, com financiamento de uma bolsa Capes, entre 2014 e 2015. Professora Adjunta do Departamento e do Programa de Pós-Graduação em História da Pontifícia Universidade Católica do Rio Grande do Sul. E-Mail: <tatyana.maia@pucrs.br>.

2 MICELI, Sérgio. Intelectuais e classe dirigente no Brasil (1920-1945). São Paulo: DIFEL, 1979. GOMES, Angela Maria de Castro. História e historiadores. Rio de Janeiro: Fundação Getúlio Vargas, 1996. PÉCAUT, Daniel. Os intelectuais e a política no Brasil: entre o povo e a nação. São Paulo: Ática, 1990. VELLOSO, Mônica Pimenta. "A brasilidade verde-amarela: nacionalismo e regionalismo paulista". Estudos Históricos, Rio de Janeiro, CPDOC, vol. 6, n. 11, 1993, p. 89-112. SEVCENKO, Nicolau. A literatura como missão: tensões sociais e criação cultural na Primeira República. São Paulo: Brasiliense, 1983.
} 
Em uma abordagem culturalista, a ênfase não é colocada numa herança biológica, [...] mas na herança cultural, ligada à socialização do indivíduo no interior do seu grupo cultural. Entretanto, o resultado é quase o mesmo, pois segundo esta abordagem o indivíduo é levado a interiorizar os modelos culturais que lhe são impostos, até o ponto de se identificar com o seu grupo de origem. Ainda assim a identidade é preexistente ao indivíduo. Toda identidade cultural é vista como consubstancial com uma cultura particular. ${ }^{3}$

Nesse enfoque, a definição da identidade resulta de uma série de determinantes objetivos como a origem comum, a língua, a religião, o território etc. A identidade seria resultado da essência cultural de um grupo, cabendo aos intelectuais o papel de difusor dessa identidade, pela investigação dos elementos formadores da cultura.

Assim, observa-se no período entre 1930 e 1970 uma constante interseção entre o campo político e o campo cultural. Somente a partir dos anos de 1970, com o fortalecimento da indústria cultural e o desenvolvimento dos programas de pósgraduação no país, intelectuais, artistas e cientistas puderam estabelecer relações mais complexas com o aparelho estatal, desenvolvendo maior autonomia frente às demandas políticas imediatas.

No interior do pensamento modernista, destaco o surgimento de uma corrente modernista-conservadora que propiciou a aproximação e a circulação de um grupo de intelectuais no interior do Estado entre os anos de 1930 e 1970, mantendo um diálogo entre os dois períodos ditatoriais - o Estado Novo (1937-1945) e a ditadura civil-militar (1964-1985). Essa corrente modernista-conservadora irá fundamentar narrativas que acionam o passado para o reforço da "corrente otimista"4 que marcou o modelo nacional-desenvolvimentista durante a ditadura. Assim, o objetivo deste artigo é investigar a construção de uma narrativa sobre a cultura e a "consciência" nacionais promovida e difundida por um grupo de intelectuais atuantes no interior do Estado brasileiro através do Conselho Federal de Cultura, CFC - órgão do Ministério da Educação e Cultura. Para tal, selecionamos a publicação em dois volumes de "História da Cultura Brasileira", obra coletiva, editada pela Fundação Nacional do Material Escolar, nos anos de 1972 e 1976.

$\mathrm{O}$ projeto modernista-conservador adotado pelos membros do CFC orientou as políticas culturais empreendidas pelo órgão e buscou definir os elementos constitutivos da cultura nacional. Associando as ideias de regional e nacional, tradição e modernidade, o projeto modernista-conservador valorizava o espírito patriótico e a existência de uma "consciência nacional" forjada desde os tempos coloniais, identificado com uma visão otimista da sociedade brasileira. A hipótese deste artigo é que a coleção "História da Cultura Brasileira", ao propor uma síntese da cultura a partir da nossa formação histórica, articula a cultura ao projeto nacional-

\footnotetext{
${ }^{3}$ CUCHE, Denys. A noção de cultura nas ciências sociais. Bauru: EDUSC, 1999, p. 179.

${ }^{4}$ FICO, Carlos. Reinventando o otimismo: ditadura, propaganda e imaginário social no Brasil. Rio de Janeiro: Fundação Getúlio Vargas, 1996, p. 34.
} 
desenvolvimentista em curso, apresentando na longa duração supostos elementos estruturantes da sociedade brasileira que sem, no entanto, adotar o caráter tecnocrático que passou a predominar em diversas agências e órgãos do Estado. Aliás, os autores de "História da Cultura Brasileira" reforçavam constantemente o caráter humanista de nossa formação.

\section{O Projeto de "História da Cultura Brasileira" no Interior do MEC}

O Conselho Federal de Cultural iniciou suas atividades em 1967, reunindo um grupo de vinte-quatro intelectuais capitaneados por Josué Montello e com larga participação em museus, arquivos, universidades e, principalmente, na Academia Brasileira de Letras e no Instituto Histórico Geográfico Brasileiro ${ }^{5}$. O projeto de criação do CFC foi formulado ainda no ano de 1965, a pedido do então ministro da Educação e Cultura Raymundo Moniz de Aragão, por uma comissão liderada por Josué Montello e composta por Adonias Filho, Augusto Meyer, Rodrigo Mello Franco de Andrade e Américo Jacobina Lacombe. O CFC, além de um caráter normativo, atuou no assessoramento ao Ministro. Na prática, até 1975, quando foram criadas outras agências e órgãos dedicados à cultura no MEC, o CFC respondeu pelas principais políticas culturais organizadas no país, incluindo a aprovação $e$ a distribuição de verbas aos pedidos de instituições, produtores e artistas submetidos ao Ministério. O CFC permaneceu atuante até 1990, sem a pujança e as atribuições dos anos de 1967-1975, que considero o período mais atuante desses intelectuais na promoção das políticas culturais do MEC.

O CFC foi responsável por instrumentalizar o Estado brasileiro no campo da cultura neste período, fomentando a criação de conselhos estaduais de cultura, propondo anteprojetos para o "Plano Nacional de Cultura", disponibilizando verbas para as instituições de cultura, públicas e privadas, apoiando diversos setores $e$ projetos culturais no setor. No entanto, ao longo de seu período mais profícuo, além das atividades previstas por seu regimento, os membros do Conselho se empenharam em organizar publicações editadas pela Fundação Nacional do Material Escolar para difusão de certa concepção sobre a cultura brasileira e seus elementos constitutivos. Dentre as publicações realizadas, destacam-se os dois projetos coletivos organizados pelo CFC, apresentados como complementares: História da Cultura Brasileira e o Atlas Cultural do Brasil. Como afirma Arthur Cézar Ferreira Reis,

\footnotetext{
${ }^{5}$ No momento de sua criação, o CFC era composto pelos seguintes intelectuais: Josué Montello, Clarival do Prado Valladares (presidente), Ariano Suassuna, Armando Sócrates Schnoor, José Candido Andrade Muricy, Octávio de Faria, Roberto Burle Marx, Adonias Aguiar Filho, Cassiano Ricardo, João Guimarães Rosa, Moyses Vellinho, Rachel de Queiroz, Arthur Cezar Ferreira Reis, Augusto Meyer, Djacir Lima Menezes, Gilberto Freyre, Gustavo Corção, Manuel Diégues Júnior, Afonso Arinos de Mello Franco, Hélio Vianna, Dom Marcos Barbosa, Pedro Calmon, Raymundo Castro Maya, Rodrigo Mello Franco de Andrade. Até 1976, ano da publicação do $2^{\circ}$ volume de História da Cultura Brasileira, houve quinze substituições de membros do Conselho, por motivos diversos. Sobre a formação inicial do CFC ver: BRASIL, Conselho Federal de Cultura. Cultura. Rio de Janeiro, MEC, ano I, n. 1, jul. 1967, p. 5-18.
} 
[...] Esta História da Cultura Brasileira é o complemento natural do Atlas Cultural do Brasil, que imaginei, planejei e fiz elaborar com a participação de companheiros do Conselho Federal de Cultura e especialistas estranhos aos quadros do Conselho, que o aprovou e fez editar como participação nas comemorações dos 150 anos de nossa independência política. $^{6}$

Logo no início de 1969, Arthur Cézar Ferreira Reis, então presidente do Conselho Federal de Cultura, apresenta a proposta da obra à Câmara de Ciências Humanas do CFC, sendo acolhida pelos integrantes da Câmara. A notícia da organização da obra coletiva logo seria divulgada através dos jornais. Ainda em fevereiro de 1969, o jornal O Globo publicava uma entrevista com Arthur Reis sob o projeto. Para Reis, a importância da obra estava no seu valor de guia, funcionando como orientador das características nacionais:

Uma obra deste alcance tem, necessariamente, de alcançar uma área maior. Ela terá uma dimensão cultural de nível superior, e é por isso que compreenderá vários volumes, abordando aspectos da Sociologia, da Arte, da Economia, da Politica e outros ângulos culturais. ${ }^{7}$

Assumiu a coordenação do projeto o sociólogo Manuel Diégues Junior, que ocupava o cargo de Vice-presidente do Conselho. Naquele mesmo ano, Arthur César Ferreira Reis, no relatório de atividades anual obrigatoriamente enviado ao gabinete do Ministro da Educação e Cultura já mencionava a existência dos projetos e a complementaridade das publicações Atlas Cultural do Brasil e História da Cultura Brasileira. No relatório, ambas as publicações eram apresentadas como "dois trabalhos marcantes" do Conselho e esperava-se que promovessem a construção de um "retrato da realidade cultural" do país ${ }^{8}$. Ambos os projetos circularam pelas quatro câmaras do $\mathrm{CFC}^{9}$, sofrendo alterações até a definição do modelo final.

A Câmara de Patrimônio ao entregar seu parecer sobre o projeto de História da Cultura Brasileira ao presidente do Conselho, durante a $177^{\mathrm{a}}$ sessão plenária, realizada em 5 de dezembro de 1969, enfatizou a necessidade de definição do conceito de cultura para a adoção de critérios e metodologias eficazes na formulação da obra. Manuel Diégues afirmou que o conceito de cultura seguia as concepções

${ }^{6}$ REIS, Arthur Cézar Ferreira. "Apresentação". In: BRASIL, Conselho Federal de Cultura. História da cultura brasileira. Rio de Janeiro: Fundação Nacional do Material Escolar, 1973, p. 1.

7 Arthur Cézar Reis em entrevista ao jornal O Globo. In: "História da cultura do Brasil espera aprovação", O Globo, Rio de Janeiro, 27 fev. 1969.

${ }^{8}$ REIS, Arthur Cezar Ferreira. "Relatório das Atividades do Exercício de 1969". Cultura, MEC/CFC, ano IV, n. 31, jan. 1970, p. 11.

${ }^{9}$ O Conselho Federal de Cultura era composto por quatro câmaras, consideradas representativas dos pilares da cultura nacional: Artes, Ciências Humanas, Patrimônio Histórico e Artístico Nacional e Letras. Ainda foi criada uma Comissão de Legislação e Normas para garantir o suporte jurídico necessário à apresentação de portarias, anteprojetos de lei ou resoluções. 
antropológicas mais genéricas, ou seja, "todas as criações do homem, de natureza material ou espiritual". Afonso Arinos insistiu na importância de uma melhor definição do conceito de cultura e por sugestão de Raymundo Faoro foi decidido que o debate envolveria todo o plenário ${ }^{10}$. Contudo, apesar das divergências iniciais, o debate parece ter se esvaziado, tendo visto que não retornou ao plenário do Conselho, prevalecendo a definição ampla, inspirada nas ciências sociais, originalmente proposta e apresentada por Manuel Diégues Júnior logo na apresentação do $1^{\circ}$ volume:

Uma História da cultura nacional, ou seja, no presente caso, da cultura brasileira não pode fugir à aceitação do conceito de cultura empregado pelas ciências sociais, e de modo especial pela Antropologia e pela Sociologia, como tudo aquilo que é criação do homem. A ideia, portanto, tem que considerar tudo aquilo que é herdado da própria sociedade ou adquirido de outras sociedades, formando assim um complexo de hábitos, ideias e criações do homem. Sentido, portanto, científico, e não exclusivamente literário. ${ }^{11}$

Após ser avaliado por todas as Câmaras do CFC, o projeto de História da Cultura Brasileira recebeu a finalização de "[...] uma comissão constituída pelos presidentes das Câmaras e da Comissão de Legislação e Normas [...] quando o plano sofreu mais sensíveis alterações"12. A divisão dos volumes seguiu a tradicional divisão temporal histórica dos séculos. Previa-se inicialmente a publicação de cinco volumes, cronologicamente organizados: os dois primeiros volumes sobre as "origens da nossa cultura"; o terceiro e quarto dedicados aos séculos XIX e XX; o $5^{\circ}$ e último volume traria os índices de toda a coleção ${ }^{13}$.

$\mathrm{Na}$ prática, apenas os dois primeiros volumes foram efetivamente publicados; o primeiro em 1973, ou seja, quatro anos após da apresentação da proposta original; o segundo, três anos mais tarde, em 1976, ambos pela FENAME, com tiragem de 2.000 cópias cada volume.

Para inventariar a recorrência das temáticas e identificar quais elementos formariam os fundamentos e o desenvolvimento da cultura brasileiro dentro do projeto modernista-conservador, procedemos a uma análise de conteúdo que relacione os aspectos inventariados pelos autores às quatro áreas definidas pelo Conselho como pilares da cultura nacional: Artes, Ciências Humanas, Letras e Patrimônio Histórico e Artístico Nacional. Busca-se compreender as chaves de leitura para a formação da cultura nacional.

\footnotetext{
${ }^{10}$ Ata da $177^{\mathrm{a}}$ sessão plenária realizada em 5 de dezembro de 1969. Cultura, MEC/CFC, ano III, n. 30, dez. 1969, p. 157.

${ }^{11}$ DIÉGUES JR., Manuel. "Apresentação". In: BRASIL, História da cultura brasileira, p. 3.

${ }^{12}$ DIÉGUES JR., "Apresentação", p. 3.

${ }^{13}$ DIÉGUES JR., "Apresentação", p. 5.
} 


\section{A 'História da Cultura Brasileira'}

O primeiro volume da coletânea foi dedicado "aos fundamentos" da cultura brasileira, divido em duas partes: primeiro, "o meio e o homem", compreendendo as origens da cultura a partir da identificação do homem inserido no meio, do contato com diversos grupos étnicos, da ocupação do espaço; e, segundo, "as instituições e os modos de vida" a partir das primeiras instituições e manifestações culturais observadas no Brasil. Dividido em doze capítulos, com 213 páginas, contou com a colaboração de 14 autores. Essa dezena de autores, com formação, trajetória profissional e perspectivas teóricas e metodológicas específicas apresenta um desafio a mais para análise aqui proposta. Se a coletânea não pode ser reduzida a uma obra homogênea dos temas selecionados, havendo diferenças nas matrizes teóricas propostas pelos autores; é possível mapear eixos analíticos que forjam uma narrativa totalizante acerca dos "fundamentos" e do "desenvolvimento" da cultura brasileira. A ideia prevalecente era de uma obra com caráter de síntese, capaz de incorporar os aspectos centrais da cultura brasileira definidos pelo regionalismo, pela unidade política e pelo papel decisivo das três etnias na formação do homem brasileiro. A circulação desses intelectuais em espaços comuns de atuação também nos informa sobre ao processo de seleção dos autores que provavelmente foi conduzido por Manuel Diégues Júnior.

E quais seriam esses fundamentos da cultura brasileira?

Uma análise do sumário já indica quais os eixos considerados centrais para a compreensão da formação cultural do Brasil: a diversidade regional, o contato de diferentes grupos étnicos, a administração portuguesa e a tradição católica. Esses temas eram recorrentes no movimento modernista desde os anos de 1920, independente das diferenças intelectuais no interior do modernismo. Assim, constróise uma tradição no pensamento intelectual brasileiro de buscar nos primórdios da nossa formação as chaves para a compreensão da realidade nacional.

Os movimentos intelectuais surgidos na década de 1920 apontavam para a urgência em definir os elementos característicos da sociedade brasileira, considerados essenciais na elaboração de diagnósticos para a superação do atraso do país. O longo debate que culminou na Semana de Arte Moderna, em São Paulo, em 1922, possibilitou a emergência de inúmeras interpretações sobre a cultura brasileira, acirrando os debates no campo intelectual. Para os modernistas paulistas do período de 1917-1924 a entrada do país na modernidade dependia do rompimento com as estruturas arcaicas e da incorporação dos padrões civilizatórios identificados com a industrialização, a urbanização e a racionalidade ${ }^{14}$.

Ainda nas décadas de 1920 e 1930, os integrantes do movimento modernista articularam a cultura à consolidação do Estado-nação com o objetivo de favorecer a construção da cidadania moderna através da formulação de representações simbólicas que gerassem um sentimento de pertencimento a uma "comunidade

${ }^{14}$ OLIVEIRA, Lúcia Maria Lippi. A questão nacional na Primeira República. São Paulo: Brasiliense, 1990. 
imaginada" ${ }^{15}$. Para André Botelho, a cultura tem um lugar central no espaço político ao se tornar uma estratégia no projeto centralizador do Estado Novo (1937-1945):

O Brasil encontrava, desse modo, sua coesão social, a cultura nacional; seus intérpretes e construtores de sentido, os intelectuais; seus portadores sociais, as elites dirigentes; e sua unicidade, o Estado. ${ }^{16}$

A constituição de uma rotina intelectual autoritária possibilitou a construção de um discurso que valorizava o papel das elites na organização social $e$ "fomentou os recursos da autoridade sobre os da solidariedade social" ${ }^{17}$. Esses intelectuais se autoproclamavam os principais agentes sociais na organização e na modernização da sociedade brasileira. Nos anos de 1960 e 1970, há um redirecionamento na compreensão do papel da cultura no universo político. Não se tratava mais de construir o Estado-Nação, tarefa já realizada pelos movimentos intelectuais dos anos de 1930 e 1940; era necessário compreender a dinâmica do processo de modernização brasileiro, seus entraves e possibilidades. Tratava-se de reconhecer quais escolhas eram compatíveis com o "ser" brasileiro, evitando a adoção de modelos "alienígenas" à nossa cultura.

O primeiro capítulo, "O quadro natural: o meio e a ocupação do território", do geógrafo Nilo Bernardes, é dedicado às especificidades do relevo, da fauna e da flora e das condições climáticas associando-as a ocupação do território pelos portugueses. A grande diversidade do meio natural haveria contribuído para diferentes ocupações territoriais, condicionando as atividades produtivas e o povoamento desigual. Nilo Bernardes, autor deste primeiro capítulo, intitulado, afirma que a permanência de ampla extensão territorial com baixa densidade populacional foi fruto das opções de ocupação do solo a partir dos interesses de cada contexto histórico no desenvolvimento de atividades produtivas e, portanto, de fixação do homem. Aliás, a diversidade regional que caracterizaria a cultura brasileira sofreu influência das condições climáticas e dos interesses produtivos em cada região do país. $\mathrm{O}$ regionalismo, portanto, marca da nossa unidade em certa medida seria fruto dessa relação do homem com o meio. Reconhecer a diversidade expressa na existência de culturas regionais como característica intrínseca ao nosso tamanho continental nos permitiria compreender melhor as bases da nossa nacionalidade.

Aliás, o autor ultrapassa a análise dos anos de formação e apresenta a situação vivida pelo Brasil dos anos de 1970. O quadro de despovoamento de certas regiões brasileiras, sobretudo, da região amazônica e do Brasil Central, começava a ser modificado pelas políticas de integração nacional. Os desafios da ocupação estavam sendo superados através da opção pela urbanização e industrialização fortemente estimulada pelos projetos modernizantes em curso. Assim, o desenvolvimento urbano-

\footnotetext{
${ }^{15}$ ANDERSON, Benedict. Comunidades imaginadas: reflexões sobre a origem e difusão do nacionalismo. Tradução de Denise Bottman. São Paulo: Companhia das Letras, 2008.

${ }^{16}$ BOTELHO, André. O Brasil e os dias: Estado-nação, Modernismo e rotina intelectual. São Paulo: EDUSC, 2005, p. 37.

${ }^{17}$ BOTELHO, O Brasil e os dias..., p. 30.
} 
industrial promovia a integração entre as regiões construindo uma nova realidade. Como afirma o autor,

[...] Sob o influxo urbano-industrial, processa-se a integração de diversas partes do País, acompanhadas de inúmeras conseqüências de caráter geográfico. A crescente intensidade da circulação terrestre corresponde ao incremento do mercado interno. ${ }^{18}$

A construção de uma trajetória linear acerca da ocupação do território, que se concentrava na presença portuguesa na América até chegar aos dias contemporâneos, desconsiderava os conflitos provocados por essa ocupação, silenciando à violência contra os povos originários ou ainda a existência de grandes latifúndios no período republicano e os conflitos de terra. Nilo Bernardes, após apresentar os oito domínios bioclimáticos existentes no país, conclui que a interiorização e a ocupação desses "espaços vazios" começavam a atrair o homem brasileiro, "[...] fascinando-o, atraindo-o, mas também desafiando-o" 19 . Como propõe Flamarion Alves, o geógrafo, atuante no Instituto Brasileiro de Geografia e Estatística, IBGE, teve suas preocupações voltadas para relação do homem com o meio, fundamentalmente na compreensão do território nacional utilizando-se do método comparativo, fortemente influenciado pela geografia francesa que marcou o chamado período clássico da geografia brasileira, afastando-se dos modelos tecnocratas que iriam prevalecer no IBGE nos anos de 1960 e $1970^{20}$.

Os próximos três textos foram dedicados a contribuição dos indígenas, dos portugueses e do negro africano na formação cultural do Brasil, numa referência a importância das três raças na formação sócio-cultural do Brasil. O capítulo "Os grupos humanos e sua contribuição" foi dividido em três sub-capítulos: "As características e as variedades dos grupos indígenas", de Marília Carvalho de Mello e Alvim; "As raízes portuguesas na formação brasileira", de Dante de Laytano; e, "Os grupos negroafricanos" de Thales de Azevedo.

Os dois primeiros subcapítulos adotam a mesma estratégia de análise temporal na compreensão da formação dos respectivos grupos. Marília Alvim inicia seu texto com a "origem do homem americano", aproveitando de sua atuação na área de arqueologia. A autora que também exercia o cargo de titular no Conselho Indigenista da Fundação Nacional do Índio, FUNAI, nos anos de 1970, tendo como colega Manuel Diégues Júnior, faz uma apresentação da ocupação da população ameríndia antes da presença dos portugueses no solo americano. O período de contato entre portugueses e indígenas no período colonial é negligenciado pela autora. Priorizando a análise antropológica à histórica, merece destaque a situação do indígena na atualidade, a diversidade linguística, a "assimilação cultural" $e$ as heranças à

${ }^{18}$ BERNARDES, Nilo. "O quadro natural: o meio e a ocupação do território". In: BRASIL, História da cultura brasileira, p. 25.

${ }^{19}$ BERNARDES, "O quadro natural...", p. 26.

${ }^{20}$ ALVES, Flamarion Dutra. "História da geografia agrária brasileira". Revista Ra'ega. Curitiba, vol. 36, abr. 2016, p. 72. 
formação da sociedade brasileira. Estas últimas poderiam ser classificadas como contributos à alimentação, às crenças folclóricas, alguns modos de viver e hábitos como o banho diário. Para a autora, mais importante do que a contribuição no campo da cultura teria sido a contribuição étnica. Apresentando a posição da FUNAI, Alvim conclui seu texto sobre a importância da incorporação do indígena a vida nacional, destacando os preceitos que fundamentavam o Estatuto do Índio como: assistência médica, investimento em educação, apoio às atividades produtivas, num processo de integração nacional salvaguardando as bases culturais indígenas e suas representações ${ }^{21}$.

Em "As raízes portuguesas da formação brasileira", de Dante Laytano, mantêm-se a estratégia narrativa de mapear as origens étnicas e culturais dos povos, neste caso da formação da sociedade portuguesa, sua diversidade cultural e temporal. Para Laytano, foi o homem português da renascença que veio desbravar as terras do continente americano. Sua narrativa, desde o princípio, concebe a existência do Brasil a partir dos chamados "descobrimentos". Assim, "o português veio para o Brasil com o descobrimento"; apresentando a historiografia brasileira dedicada à compreensão da participação "portuguesa, das raízes portuguesas da formação do Brasil"22. A maior contribuição da colonização portuguesa foi "a doutrina da centralização do poder", que permitiu a manutenção da unidade, da autoridade do Estado, conformando nos espíritos a importância da homogeneidade na construção da sua civilização.

Tal como registrou Orlando Ribeiro, a população portuguesa, em que pesem suas variações regionais, mostra elevado grau de homogeneidade, de que resultou o contato com outras terras e outras gentes, resistir a qualquer desagregação. $O$ caso do Brasil: dessa virtude o Brasil tornou-se herdeiro, aclimatando-a e herdando-a em sua formação. ${ }^{23}$

O estabelecimento de um padrão cultural singular para a formação da sociedade brasileiro está alicerçado na dinâmica portuguesa, com seus tipos, ordenações, saudades e unidade. Para o autor, o predomínio dos "padrões culturais portugueses" não impediu a incorporação das raízes indígenas e africanas; ao contrário, o caráter plástico do português possibilitou o amálgama entre as três etnias, favorecendo a transformação desses "padrões culturais portugueses" em "padrões luso-brasileiros, ou melhor, luso-afro-índios-brasileiros, com as peculiaridades regionais". No campo administrativo, as ordenações foram responsáveis pela centralidade do Estado na conformação da sociedade; pelo paternalismo, pela unidade política e territorial. A

${ }^{21}$ ALVIM, Marília Carvalho de Melo. "As características e variedades dos grupos indígenas". In: BRASIL, História da cultura Brasileira, p. 45.

${ }^{22}$ Dentre os historiadores mencionados, estão os clássicos Capistrano de Abreu e Varnhagem, e vários membros do Conselho Federal de Cultura: Arthur Cezar Ferreira Reis, Pedro Calmon, Gilberto Freyre, Moises Velhinho, Hélio Vianna. Também citou "historiadores" contemporâneos como Sérgio Buarque de Hollanda, Oliveira Lima, Honório Rodrigues, Otávio Tarquínio de Souza. LAYTANO, Dante. "As raízes portuguesas da formação brasileira". In: BRASIL, História da cultura brasileira, p. 56.

${ }^{23}$ LAYTANO, "As raízes portuguesas...", p. 57. 
unidade, contudo, ia além do campo político, segmentado pela tradição cultural portuguesa alicerçada na "unidade da família e a unidade religiosa".

O subcapítulo "Os grupos negro-africanos contrasta com os dois anteriores" concentra-se apenas na presença dos negros africanos na colônia, sem mencionar a trajetória de ocupação e povoamento das regiões do continente africano de onde os negros foram trazidos. De autoria de Thales de Azevedo, o texto concentra-se na participação do negro como mão-de-obra escrava, sem desconsiderar a violência da escravidão, as discriminações e os abusos ao qual estavam sujeitos. A influência dos negros na formação social teria ficado restrita às manifestações culturais populares festas, comidas típicas, religiões animistas, crendices e lendas. A mestiçagem aparece circunscrita às relações inter-raciais cuja expressão maior seria o mulato. No campo da cultura letrada, menciona a existência de literatos negros ou mestiços, ou da presença negra na produção cultural brasileira.

O terceiro capítulo é dedicado à invasão e presença dos holandeses em Pernambuco. "Outras contribuições: os Holandeses", de José Antonio Gonsalves de Melo Neto, faz uma descrição da presença holandesa na região, optando por uma narrativa linear e descritiva, dentro dos cânones da tradicional história política. A pouca importância dada à presença holandesa no período colonial revela a importância da leitura sobre as três etnias à formação histórica e cultural brasileira. Assim, portugueses, indígenas e negros africanos formavam a base étnica que estruturava a sociedade brasileira.

Para encerrar as discussões sobre o "Meio e o Homem", o capítulo "Expansão do povoamento e a definição territorial do Brasil" de Arthur Cezar Ferreira Reis, presidente do Conselho Federal de Cultura. Retomando a trajetória da ocupação do território apresentada nos capítulos anteriores, Reis vincula os tipos de ocupação aos interesses nas atividades produtivas e também às condições climáticas e de relevo. Enquanto que a ocupação do território pela faixa litorânea foi obra do Estado português, a ocupação do sertão foi fruto da iniciativa privada, sobretudo, bandeirante. O domínio de vasta extensão territorial dependeu da presença do Estado. Novamente, o Estado é acionado como o principal agente na manutenção da unidade:

Esse domínio era exercido pela autoridade política, civil $e$ militar, pela autoridade religiosa, como parte integrante do poder nacional, pela incorporação das multidões nativas $e$ pela instalação dos grupos demográficos no exercício do povoamento e da colonização. ${ }^{24}$

O vazio provocado pela baixa densidade demográfica era contrabalanceado pela mestiçagem "intensiva, atuante e impiedosa" capaz de resistir à presença estrangeira. Somente no século XVIII, as ações políticas favoreceram a existência de uma "política de preservação e de consolidação do espaço" 25 . Contudo, a construção da nação

\footnotetext{
${ }^{24}$ REIS, Arthur Cesar Ferreira. "Expansão do povoamento e a definição territorial do Brasil". In: BRASIL, História da cultura brasileira, p. 100.

${ }^{25}$ REIS, "Expansão do povoamento...", p. 101.
} 
também é fruto da emergência de uma "sociedade solidária", em regiões onde o Estado foi muitas vezes ausente. Essa oscilação entre a presença de um Estado forte $e$ a existência de movimentos de ocupação e fixação do homem independente da presença estatal é recorrente no texto de Arthur Reis. Para finalizar o texto, Reis menciona brevemente a ocupação do espaço no Império e na República, oscilando novamente entre ações da empresa privada e políticas de integração como as rodovias que avançavam sobre a floresta amazônica: Belém-Brasília, Brasília-Acre e da Transamazônica. Na prática, a criação dessas rodovias não foi suficiente para integração desses espaços ou adensamento populacional; os gastos vultosos com essas rodovias são apontados pela historiografia como opções equivocadas no modelo de desenvolvimento brasileiro.

A segunda parte da coletânea debruçou-se sobre as "instituições e modos de vida", quais sejam: a língua, a escravidão, a organização administrativa, a defesa militar, a religião católica, o artesanato, o ensino, e por fim, a recreação popular. O capítulo sobre a língua, escrito por Gladstone Chaves de Mello, apresentava a língua como fator de integração. Novamente, a ideia unidade também se faz presente; afinal, "a língua é um dos mais poderosos fatores de coesão e de unidade". A existência de uma língua comum, por outro lado, não significa a ausência de elementos diversificados ou regionais. Os diferentes modos de falar terão "pontos de encontro" que favorecem a comunicação em comum. Assim, a unidade $e$ a diversidade não excluem mutuamente, ao contrário, tal como nos demais aspectos da vida cultural convivem na formação de um sentimento de pertencimento:

Ora, repito e insisto, poucos países terão unidade nacional tão forte como o Brasil. Apesar da intensidade do território e dos regionalismos, todos nós nos sentimos profundamente brasileiros. E um dos cimentos dessa unidade é a língua.

Utilizando-se da expressão cunhada por Arthur Reis, Gladstone Mello vai afirmar que até períodos recentes constituíamos um arquipélago, devido às elevadas áreas de baixa densidade populacional e das diferenças regionais. Contudo, o fator unificador teria sido a língua em comum. Assim, a língua portuguesa teria exercido papel singular como elemento de coesão. Outro elemento de formação da nacionalidade foi à escravidão. Para José Arthur Rios, autor do capítulo "A propriedade da terra, o patriarcalismo e a escravidão", o tráfico de escravos e o uso intensivo da mão-de-obra dos negros africanos nas lavouras, no serviço doméstico, nas ruas das vilas e cidades, das minas de ouro e diamantes, ou seja, no dia-a-dia da colônia e do império marcaram a vida coletiva. O reconhecimento do papel da escravidão na formação socioeconômica brasileira não significou uma reflexão exaustiva do autor. Ao contrário, concentrou-se na narrativa descritiva, com destaque para alguns movimentos de resistência à escravidão, a atitude violenta dos senhores de escravos $e$ a tentativa pouco eficaz da Corte em conter os abusos cometidos pelos donos de escravo. Na prática, os dois capítulos que deveriam ser dedicados à presença e à importância dos negros africanos na formação da sociedade se circunscreveram a 
tratar o lugar do negro africano prioritariamente como força produtiva, ressaltando os aspectos econômicos e políticos do uso da mão-de-obra escrava.

Os aspectos culturais e o protagonismo dos negros na formação da nacionalidade pertencem a uma discussão recente, ainda carente de análises mais pormenorizadas nos anos de 1970. Só esporadicamente há a menção da participação ativa do negro na construção da sociedade brasileira. Aliás, se observamos no conjunto, os textos priorizam os aspectos lusitanos, a organização política, a importância religiosa, a língua de Camões. Há uma clara hierarquização das etnias que comporiam a cultura brasileira. Os três próximos capítulos, por exemplo, seriam dedicados aos aspectos administrativos, políticos e eclesiásticos; a defesa militar e as instituições religiosas, com destaque para o papel dos jesuítas ${ }^{26}$. A História da Cultura Brasileira reservou um amplo espaço para textos e temas relacionados à História Política tradicional, ou seja, optando por uma História cronológica, linear, descritiva, preocupada em demonstrar a formação cultural a partir das ideias de unidade, integração $e$ diversidade regional, com predomínio do papel do Estado e das tradições culturais portuguesas sobre as demais contribuições.

Os três últimos capítulos são sobre o artesanato, a educação e a recreação popular. Em "Artes e os ofícios - o artesanato", Vicente Salles concentra sua análise na apresentação da cerâmica, das embarcações, da fiação e tecelagem, das pinturas $e$ esculturas. Prioriza o popular, com destaque para a produção das manufaturas indígenas. Prevalece a leitura de um artesanato rudimentar, que recebeu poucos investimentos para o seu pleno florescimento. O capítulo "Os primórdios da educação - a família e o ensino", de Américo Jacobina Lacombe, apresenta o papel dos jesuítas na educação colonial como moralizadores da vida desregrada dos anos iniciais da colônia. Na falta de investimento na área do ensino coube aos jesuítas e demais ordens religiosas assumirem a educação. Para encerra o primeiro volume, um capítulo sobre as festas populares desde a colônia até os dias mais recentes. O capítulo "A recreação popular, suas formas e expressão", de Renato Almeida, irá apresentar brevemente as festas populares realizadas em diferentes partes do país, novamente, destacando o caráter regional desses festejos. Assim, serão retratados brevemente as touradas, as cavalhadas, o entrudo, a festa do Divino Espírito Santo, os congos e congadas, a festa do Senhor do Bonfim, a festa da Penha, o Círio de Nazaré, o Bumba-meu-boi e festas religiosas diversas como as juninas e as do Natal. As festas religiosas, inspiradas na tradição católica, dominam a seleção de festas descritas pelo autor. Assim, observa-se a valorização do catolicismo frente às demais matrizes religiosas, sobretudo, às religióes de matriz afro-brasileira.

O segundo volume, publicado três anos depois, tratou do "desenvolvimento da cultura" desde os primórdios coloniais até as vésperas da independência. Esse volume foi dividido em três partes: "As primeiras manifestações culturais", "A cultura no século XVIII" e "A transmissão da cultura". Era maior do que o primeiro, com dezoito capítulos, vinte e um autores e 392 páginas. Em ambos os volumes, as imagens

\footnotetext{
${ }^{26}$ São eles: FAORO, Raymundo. "A organização administrativa, política e eclesiástica". In: BRASIL, História da cultura brasileira, p. 115-128. SANTOS, Francisco Ruas. "A defesa do espaço físico". In: BRASIL, História da cultura brasileira, p. 141-156. LIMA, Alceu Amoroso. "As instituições religiosas". In: BRASIL, História da cultura brasileira, p. 157-170.
} 
pertenciam ao acervo do Instituto do Patrimônio Histórico e Artístico Nacional, ao Clarival do Prado Valladares e a Marcel Gautherot, os responsáveis pela seleção e coordenação iconográfica dos volumes.

$\mathrm{Na}$ apresentação desse segundo volume, Manuel Diégues Júnior reconhece a distância temporal entre as duas publicações; porém, insiste que tal como no volume anterior, esta coletânea faz jus aos propósitos do Conselho Federal de Cultura, sendo representativa do trabalho desenvolvido no interior do órgão. A coletânea traz como corte o século XVIII e o início do século XIX, até as vésperas da independência. A importância da arquitetura e dos bens móveis é perceptível no espaço destinado à temática no interior da coletânea. O capítulo "As artes plásticas", sobre a arquitetura $e$ o estilo barroco, foi subdividido em três capítulos menores: "Arquitetura civil e religiosa", de Paulo Barreto; "Arquitetura Militar", de Francisco Ruas Santos; e "Talha, imaginária, pintura e mobiliário", Lygia Martins da Costa, num total de 89 páginas, sem dúvida, o maior capítulo da coletânea.

No período de 1930-1970, o Barroco ganha destaque como expressão cultural original, sendo priorizado pelas políticas de proteção do patrimônio. No interior do Conselho Federal de Cultura prevaleceu a mesma concepção do Serviço do Patrimônio Histórico acerca dos estilos arquitetônicos que deveriam ser priorizados. Conforme demonstra Maria Cecília Londres Fonseca, até a década de 1960 o SPHAN manteve-se centrado no patrimônio de pedra e cal; a prática dos tombamentos, principal área de atuação do órgão, privilegiou a definição estética, seguida do valor histórico, elegendo obras consideradas de alto valor artístico, hierarquizando-as conforme o estilo: barroco, neoclássico, moderno e eclético ${ }^{27}$.

A visão do patrimônio como elemento indispensável à civilização e à modernidade, institucionalizada na gestão de Rodrigo Mello Franco de Andrade, foi claramente apropriada pelos integrantes do $\mathrm{CFC}$ e manteve-se incorporada às suas práticas, afinal, muitos daqueles que participaram do SPHAN, integraram-se ao CFC. Contudo, o Conselho ampliou a noção de patrimônio, incorporando ao conceito os hábitos, costumes, danças, modos de agir e pensar, invenções nas áreas científicas $e$ artísticas etc. Essa definição ampla do patrimônio foi apresentada nas Diretrizes para uma política cultural, em 1973, documento responsável por ordenar o papel do Estado na cultura, dando-lhe fundamentação teórica, constituindo uma definição sobre a função da política cultural e seus pilares de ação:

[...] constituído das tradições históricas e dos hábitos $e$ costumes estratificados; das criações artísticas e literárias mais representativas do espírito criador brasileiro; das realizações técnicas e científicas de especial significação para a humanidade; das cidades, conjuntos arquitetônicos $e$ monumentos de significação histórica, artística, cívica ou religiosa; das jazidas arqueológicas, das paisagens mais belas

${ }^{27}$ FONSECA, Maria Cecília Londres. O patrimônio em processo: trajetória da política federal de preservação no Brasil. 2. ed. Rio de Janeiro: Ed. UFRJ/ MinC/ IPHAN, 2005, p. 115. 
ou típicas do território pátrio; das idéias e ideais partilhados pelos brasileiros. ${ }^{28}$

Ao contrário do primeiro volume, onde predomina a análise da formação socioeconômica, com forte viés político, observa-se neste segundo volume, a hegemonia de temas específicos da cultura: as expressões literárias; a oratória; a arquitetura e o mobiliário; a música; o teatro e a dança; as ciências naturais $e$ médicas; as técnicas de trabalho; o movimento barroco, as artes plásticas; as sociedades e clubes; o ensino; os impressos. Apenas o capítulo de Leandro Tocantins, "Ideias políticas do século XVIII e a sua repercussão no Brasil" é dedicado ao campo do político. Na construção de um "nacionalismo" cultural, dois capítulos merecem destaque: "As primeiras manifestações de nacionalismo literário" de Vianna Moog; e "Manifestações de autonomia literária". A Escola mineira e outros movimentos, de Dom Marcos Barbosa. Nessa coletânea, apenas cinco autores eram membros do CFC: Dom Marcos Barbosa, Manoel Caetano Bandeira de Mello, Vianna Moog, Raymundo Moniz de Aragão e Pedro Calmon.

A trajetória histórica e a seleção de elementos que caracterizem a nacionalidade brasileira e sua singularidade frente a outros países são recorrentemente acionadas. A carta de Pero Vaz de Caminha é citada como uma das primeiras expressões literárias do Brasil ou ainda como o documento primeiro de registro da nova terra. A formação da consciência, do espírito, da sensibilidade, da imaginação depende sobremaneira da compreensão da literatura brasileira. Para José Aderaldo Castelo, autor do subcapítulo "Em prosa", a Carta é a expressão primeira da prosa do Brasil. No século $\mathrm{XVI}$, os jesuítas e cronistas produzem retratos do nosso índio e da ocupação do território. Se a Carta era o nosso documento de fundação, com características literárias, seria a força do meio ambiente e do processo de mestiçagem que nos garantiria a independência literária. No subcapítulo, "Em verso", de Manoel Caetano Bandeira de Mello, a ideia do meio como elemento constitutivo das especificidades da nossa nacionalidade e da mestiçagem como leitura da nossa formação social retorna à literatura. Para Manoel Mello, a independência literária teria fomentado os espíritos preparando-os para a independência política que ocorreria no início do século XIX.

O papel dos jesuítas e das ordens religiosas novamente será objeto de atenção na coletânea. Os capítulos sobre "A oratória sacra: as cartas e a literatura religiosa", de Ivan Lins; Quadro geral do ensino: formação das instituições pedagógicas, de Raymundo Moniz de Aragão; e "Ensino Humanístico, os colégios jesuítas, as humanidades, as aulas superiores", de Pedro Calmon; "Seminários de Olinda e outros Seminários", de Newton Sucupira, demonstram a importância dos jesuítas na Educação no período colonial, quando os investimentos em educação pública e no nível superior foram praticamente inexistentes. Em todos esses capítulos, prevalece a importância da tradição humanística na formação do espírito nacional, contrastando com os discursos tecnocratas que alimentaram parte considerável de órgãos $e$ agências do governo no período da ditadura militar. $O$ crescimento da tecnoburocracia no interior do Estado retirava dos intelectuais atuantes no aparelho

${ }^{28}$ CONSELHO Federal de Cultura. "Diretrizes para uma política nacional de cultura". Boletim do Conselho Federal de Cultura. Rio de Janeiro, MEC, ano III, jan./mar. 1973, n. 9, p. 60. 
estatal desde os anos de 1930 a primazia da orientação dos projetos políticos em curso. Reforçar a nossa essência cultural humanística era, sobretudo, reforçar o papel dos intelectuais na compreensão da realidade nacional e na orientação dos destinos políticos da nação.

Para fins de análise do conteúdo, iremos nos deter aos três artigos que explicitam em sua construção narrativa a tentativa de apresentar existência de um nacionalismo ou autonomia frente à Europa no campo da cultura desde o período colonial: "Primeiras manifestações de nacionalismo literário", de Viana Moog; "O movimento barroco" de Fernando Correa Dias; "Manifestações da autonomia literária: a Escola Mineira e outros movimentos" de Dom Marcos Barbosa.

Vianna Moog, ao contrário de Gladstone Chaves de Mello, afasta-se das leituras que consideram a Carta de Pero Vaz de Caminha como nossa primeira manifestação literária, ainda que reconheça a monumentalização do documento. Historicizando o conceito ou o termo "brasileiro", Moog chama atenção para o fato de que o termo não produzia como sentido a existência de um sentimento nacional. Quanto à produção literária, seria possível identificar nos primórdios do século XVII, algumas obras que indicavam positivamente a existência de um nacionalismo, ainda que incipiente. Esse seria o caso da obra Prosopopéia, de Bento Teixeira Leite ou ainda Diálogos da Grandeza do Brasil, de Ambrósio Fernandes Brandão. Para Moog, destaca-se no quadro de manifestação literária de caráter nacional, a contribuição jesuíta dos séculos XVI e XVII. Afinal, na compreensão de Moog, a exaltação positiva à terra seria o elemento principal do nacionalismo:

O sentimento de amor à terra onde deriva em última análise o instinto de brasilidade está de alguma forma presente em todas elas. Ainda que algumas tenham sido escritas a título apenas de propaganda, para fomentar a imigração de que se descuidava o Reino, acabam todas de um modo ou de outro portadoras de mensagens de fundo nacionalista. ${ }^{29}$

A partir do século XVIII, as narrativas literárias já ultrapassam a simples exaltação da terra e da natureza, passando a incluir "o homem, as bandeiras, o indígena, o mameluco, numa palavra, o brasileiro e seus feitos" ${ }^{30}$. Moog identifica nos jovens letrados brasileiros os "precursores da nacionalidade, citando Gregório de Matos, Alexandre de Gusmão, José Bonifácio, Basílio Gama e Gonçalves Dias. Porém, não deixa de registrar a permanência dos traços culturais portugueses na estrutura formativa desses jovens: "sentimentalidade católica, o mesmo apego a família [...] a mesma língua" ${ }^{1}$. Essa nacionalidade brasileira que carrega traços marcantes da cultura lusitana é recorrente em nossos intelectuais, que preferem identificar-se com as matrizes européias, do que com as contribuições dos indígenas e negros africanos. Contudo, para Moog, nosso processo de autonomia cultural só se concretizaria com a

\footnotetext{
${ }^{29}$ MOOG, Clodomir Vianna. "Primeiras manifestações de nacionalismo literário". In: BRASIL, História da cultura brasileira, p. 216.

${ }^{30}$ MOOG, "Primeiras manifestações...", p. 219.

${ }^{31}$ MOOG, "Primeiras manifestações...", p. 221.
} 
Semana de Arte Moderna de 1922, ano das comemorações do Centenário da Independência, numa clara filiação ao movimento modernista.

O movimento modernista foi considerado por Fernando Correa, autor do capítulo "Movimento Barroco", como o responsável por valorizar a estética barroca e colocá-lo no centro da vida intelectual brasileira. Como já apresentamos, o modernismo expresso no interior do SPHAN e no CFC irá considerar o barroco mineiro a maior expressão da nossa autonomia arquitetônica, expressão-máxima da nacionalidade no século XVIII. Sua originalidade frente às manifestações culturais europeias the dotavam de características únicas. A partir da atuação dos modernistas no SPHAN as cidades mineiras tornaram-se o centro da política de preservação do patrimônio no Brasil. Para Correa, a urbanização, a miscigenação e a maior mobilidade social permitiram que surgisse uma expressão artística única como o barroco. $\mathrm{O}$ mulato adquiria um lugar de destaque nessa estrutura social, menos rígida que em outras regiões coloniais. Ele seria o representante do processo de miscigenação em curso. A construção de uma "consciência regional" em Minas teria fomentado movimentos como a inconfidência, o federalismo e o movimento modernista. Aspectos como originalidade $e$ autenticidade, caros ao debate do patrimônio, poderiam ser identificados nas cidades coloniais mineiras. $E$ isso que as credenciaria como patrimônio cultural do país.

Por fim, o capítulo "Manifestações de autonomia literária: a escola mineira e outros movimentos", de Dom Marcos Barbosa. A chamada "escola mineira", na segunda metade do século XVIII, seria representativa dos primeiros indícios de manifestação literária nacional. Os autores que integravam a escola seria Basílio da Gama, Santa Rita Durão, Cláudio Manuel da Costa, Tomás Antonio Gonzaga e Alvarenga Peixoto. Neste grupo prevalecia o sentimento nativista mais do que a expressão de um nacionalismo bem definido. Contudo, os ecos da inconfidência se fariam presentes em seus poemas e escritos, ávidos por celebrar os conspiradores e autonomia do Brasil.

Esses três capítulos reconstroem as manifestações literárias dos séculos XVII e XVIII buscando encontrar nelas elementos que sustentem o nacionalismo que irá marcar o modernismo-conservador presente no interior do Estado brasileiro, através de intelectuais fortemente atuantes no campo cultural entre 1920 e 1970. O volume 2 de "História da Cultura Brasileira" buscou recuperar as origens da nacionalidade nas obras literárias e na arquitetura, com predomínio para o nativismo e o barroco.

\section{Considerações Finais}

A coletânea, organizada em dois volumes, irá reconstruir a trajetória sociocultural da sociedade brasileira, buscando compreender os aspectos de formação de nossa nacionalidade. É recorrente nos textos, a importância do meio na construção de um regionalismo como características da nação; da superioridade do português frente aos índios e negros na formação do país, na religião católica. Elementos culturais $e$ psicossociais se misturam, evidenciando características específicas da tradição lusitana: o apego à família, a cordialidade, a capacidade de adaptação. Por fim, a miscigenação teria resultado no mulato, síntese do homem nacional. Ainda que 
dedicados aos séculos XVI, XVII e XVIII são inúmeras as referências ao Brasil contemporâneo e a importância do movimento modernista na redescoberta do Brasil.

Infelizmente, História da Cultura Brasileira não completou o ciclo previsto de cinco volumes, divididos cronologicamente. Não constam nas atas e documentos oficiais do Conselho as causas que levaram a interrupção do projeto. A partir de 1975, o setor cultural do MEC passaria por profundas transformações e o CFC perderia a maior parte de suas atribuições. Talvez, o enfraquecimento do órgão tenha acarretado a paralisação de seus principais projetos.

$\mathrm{O}$ conceito de cultura brasileira proposto pelos intelectuais do CFC faz-se presente ao logo dos dois volumes da coletânea. Pode-se considerar que havia um microclima de época, que produzia leituras sobre a cultura nacional ancorada nas análises antropológicas, definindo-a como um patrimônio formado desde o processo de conquista e colonização portuguesa, portanto, por aspectos de longa duração $e$ singulares que permitem a distinção do Brasil em relação às demais nações.

Ora, há, no Brasil, uma cultura, a cultura brasileira, que é a construção que vimos promovendo, nós, o povo brasileiro, no continente-arquipélago que constituímos e nos distingue no cenário mundial. A cultura brasileira, com cerca de quinhentos anos de passado, [...] é patrimônio de que nos podemos orgulhar porque é fruto de nossa constância, de nossa dramática atividade criadora como sociedade que se afirma desde a luta contra a natureza, rica e muitas vezes difícil, à construção de centros de revolução urbanística dos tempos novos que o mundo vive, como é o caso de Brasília. ${ }^{32}$

O patrimônio nacional, tal como proposto pelo CFC, incluía as obras artísticas e arquitetônicas de valor histórico, os museus, as bibliotecas, os teatros, as academias de letras e os institutos históricos, as cerimônias cívicas, as grandes obras da literatura, as festas populares, os centros históricos. Assim, como afirma Nestor Canclini, o patrimônio é o cenário dedicado à "comemoração do passado legítimo" e aos aspectos da verdadeira "essência nacional". O patrimônio torna-se, então, o representante máximo da nacionalidade. Investir no patrimônio é investir na cultura nacional.

As únicas operações possíveis - preservá-lo, restaurá-lo, difundi-lo - são a base mais secreta da simulação social que nos mantêm juntos [...]. A perenidade desses bens leva a imaginar que seu valor é inquestionável e torna-os fontes do consenso coletivo, para além das divisões entre classes, etnias

\footnotetext{
${ }^{32}$ Discurso realizado por Arthur C. F. Reis durante a cerimônia de posse do Prof. Raymundo Moniz de Aragão da presidência do Conselho Federal de Cultura. CONSELHO Federal de Cultura. Boletim do Conselho Federal de Cultura, Rio de Janeiro, MEC, n. 9, jan./mar. 1973, p. 12.
} 
Essa visão do patrimônio está relacionada à concepção substancialista da cultura presente nos discursos dos intelectuais. São esses homens que definiram o "alto valor de certos bens culturais: os centros históricos das grandes cidades, a música clássica, o saber humanístico. Incorporaram também bens populares sob o nome de folclore [...]"34. A questão do patrimônio tornou-se a grande bandeira de atuação do Conselho Federal de Cultura. Não somente o patrimônio de pedra e cal. Mas, todo o legado cultural brasileiro expresso nas artes, na literatura, no folclore.

\section{$\operatorname{son} 2$}

\section{RESUMO}

O objetivo deste artigo é compreender as chaves de leitura acerca da cultura nacional proposta pelos intelectuais modernistas-conservadores no interior do MEC - Ministério da Educação e Cultura, entre 1972 e 1973, a partir dos dois volumes de História da Cultura Brasileira. Essa coletânea, organizada pelo CFC - Conselho Federal de Cultura e publicada pela FENAME - Fundação Nacional do Material Escolar, tinha como propósito elaborar uma síntese da cultura brasileira em cinco volumes. O projeto modernista-conservador elaborado pelos intelectuais do CFC terá amplo espaço de divulgação a partir dessas obras coletivas, cujo resultado esperado era a construção de narrativa sobre o passado que identificasse os elementos formadores da cultura e da consciência nacional.

Palavras Chave: Intelectuais; Cultura Nacional; Políticas Públicas.

\section{ABSTRACT}

This article aims understand the keys to reading about national culture proposed by the modernistconservative intellectuals in the MEC - Brazilian Education and Culture Ministry, between 1972 and 1973, from the two volumes of Brazilian Culture History. This collection, organized by the CFC - Federal Culture Council and published by FENAME - National Foundation for School Supplies, aimed to elaborate a synthesis of Brazilian culture in five volumes. The modernist-conservative project elaborated by the CFC intellectuals will have ample space for dissemination from these collective works, whose expected result was the construction of narrative about the past that identified the formative elements of culture and national consciousness.

Keywords: Intellectuals; National Culture; Public Policies.

Artigo recebido em 15 mai. 2017.

Aprovado em 26 jun. 2017.

\footnotetext{
${ }^{33}$ CANCLINI, Nestor García. Culturas híbridas: estratégias para entrar e sair da modernidade. Tradução de Heloíza Pezza Cintrão e Ana Regina Lessa São Paulo: EDUSP, 2000, p. 160.

${ }^{34}$ CANCLINI, Culturas híbridas..., p. 160-161.
} 